\title{
In an Era of Autonomous Vehicles, Rails are Obsolete
}

\author{
Yair Wiseman \\ Computer Science Department \\ Bar-Ilan University \\ Ramat-Gan 52900, Israel \\ wiseman@cs.biu.ac.il
}

\begin{abstract}
In few years autonomous vehicles will be nothing special in many countries. These vehicles will noticeably change the worldwide transport market. One of the noteworthy changes will be the leaving behind of rail systems, because of a number of essential rationales. The most significant rationales are: (a) Autonomous vehicles are much safer than trains and the chances for a car accident will be very low. (b) Traffic jams and congestions will be considerably reduced, so they will not be a good enough reason for rails anymore. (c) Modern autonomous cars pollute Earth's atmosphere roughly just as rails pollute and both of the pollutions have been significantly reduced. (d) Disableds will prefer autonomous cars over rails.
\end{abstract}

Keywords: Autonomous Vehicles, Computers Replace Humans, Rails, Transportation Means.

\section{Introduction}

Nowadays, most of the countries maintain rail systems and even subsidized then because of four main rationales:

A. If some of the passengers in the vehicles travel by trains, the roads will be less congested [1].

B. There are people who are not capable to drive because of a disability or because they are tired or drunk and trains can be an answer for their transportation needs [2].

C. The passengers of many cars can be put in one train, so less air pollution will be generated [3].

D. Trains considered as a safer means of transportation because statistically there are less accidents and fatalities in rail systems compared to vehicles we have today [4].

Nowadays, some of these rationales can be to a certain extent applicable. However, when autonomous cars are available, these rationales will not be relevant anymore. In Phoenix, autonomous vehicles of Waymo, will be available with no driver as early as 2018 [5]. In this paper we will explain why all of the rationales for rails are not applicable any longer.

Each of the sections in this paper from 2 to 5 clarifies why the rationales listed above from $\mathrm{A}$ to $\mathrm{D}$ (relatively) are not valid rationales for rails in a world with autonomous vehicles.

\section{Autonomous Vehicles are not Less Safe than Rails}

Received (December 6, 2017), Review Result (February 5, 2018), Accepted (February 12, 2018) 
The question whether trains are safer than private cars is far from certain. In 2015, there was a much smaller number of fatalities in rail accidents than the number of fatalities in vehicle accidents. 35,092 people died in The United States in highway crashes during 2015, whereas only 749 people died in The United States in rail related accidents in the same period [6].

However, currently the travels in the US are mainly undertaken by cars; whereas rails carry only a small fraction of passengers. According to the US Department of Transportation, 3,130,509 million miles were traveled on US highway system in 2015; whereas rails were the means of transportation for only 532 million miles that were traveled in the same period [7].

Rail accidents are usually rarer, but when rail accidents happen, statistically more people will be killed [8]. On the other hand, simulations of traffic accidents show that more damages are caused to car bodies in accidents, because they are feebler than rail bodies $[9,10,11]$. As a result, road crashes impose more significant costs. In point of fact, the annual cost of road crashes is USD \$518 billion worldwide, costing individual countries from $1 \%-2 \%$ of their annual GDP [12].

In [13] the author claims that in cities where the rail transit is a major component of the transportation system, there will be $36 \%$ lower per capita traffic fatalities 7.5 versus 11.7 annual deaths per 100,000 residents. So, in one way or another it is unclear whether the rail system is safer or not.

In spite of this uncertainty, numerous authorities in many countries accept as true that many lives can be saved by shifting some of the travels from private cars to rail systems.

As was explained above, it is unsure whether rail systems are a safer means of transportation; however, when autonomous vehicles are available, it will be unquestionable that autonomous vehicles are much safer $[14,15,16]$; Therefore, it is irrational to encourage people to travel in rails by subsidizing this more unsafe means of transportation. Experts believe that by automating driving, 95\% of car crashes can be eliminated [17], because they will have many sensors $[18,19,20]$ that will work in parallel and will never get sleepy.

On the other hand, rails will also become autonomous [21]; therefore, their safety will also significantly increase similarly to the increased safety of the autonomous vehicles.

Consequently, in the era of autonomous vehicles the answer for the question of which means of transportation is safer, will be that it is unlikely to die in road accident and it is hard to determine which means of transportation is safer because the number of accidents is extremely small.

\section{Rails are not the Answer for Traffic Congestions}

Different ways of driving and different responses to events in the roads by different drivers are the most common explanation for traffic jams and traffic congestions suggested by several studies in various countries [22,23]. In contrast, autonomous vehicles of even competing companies carry out the driving tasks very similar, so the nuisance of traffic congestions is going to be considerably relieved when the autonomous vehicles will be the standard vehicles.

Also, street parking takes up space that could be used for moving traffic [24], because an empty autonomous vehicle can move by itself to a remote parking which means uncomplicated increase of road capacity.

In addition, using the money saved from eliminating the subsidization of rail systems for expanding and constructing roads can also help to relieve congested roads. On the whole, all the countries except of Japan subsidize their rail systems. China finances $\$ 128$ billion for rails each year [25], whereas Europe finances $€ 73$ 
billion for rails each year [26]. Practically, the subsidizations are a main financial share of rail system budgets almost in all the countries. Without these subsidizations almost no rail system can continue to exist.

If the rail subsidizations are eliminated, the rail companies will not be able to pay their bills and they will go bankrupt because in point of fact rail systems lose billions of dollars every year. Only freight rails in a number of their lines in some circumstances can be profitable [27]. Closing rail systems will save billions of dollars of subsidizations and these saved billions of dollars can be invested in roads to facilitate alleviation of traffic congestions.

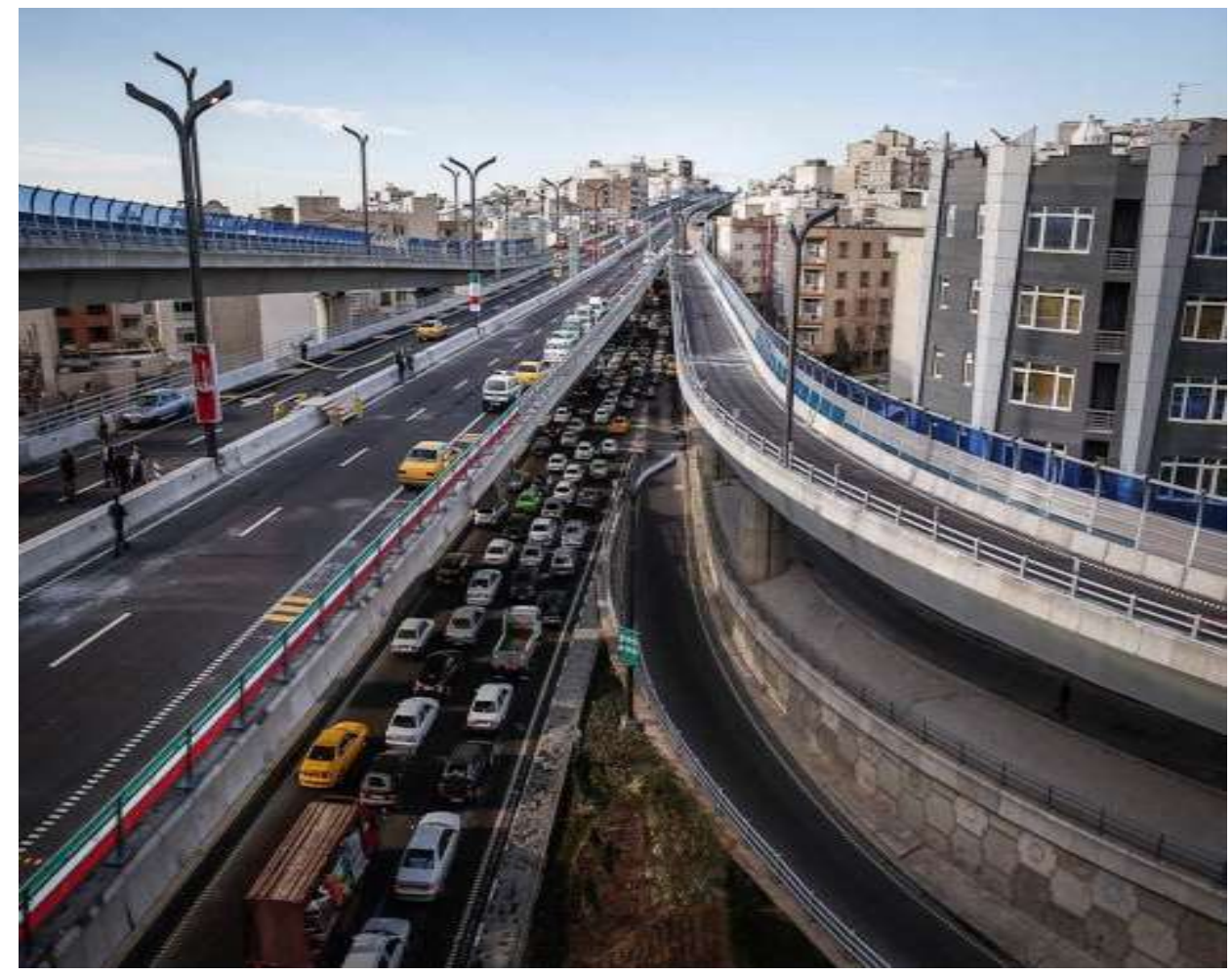

Figure 1. Second Floor of Roads in Tehran, Iran

In many places an expansion of the road is the most practical solution for traffic congestions $[28,29,30]$; however, there are places where the roads cannot be expanded because there are buildings near the roads or some other reasons. In roads where an expansion is impossible, a second floor of lanes should be built on the old road as an alternative for the expansion the same as was done in Kobe, Japan, Chicago, USA and many other places in the world [31].

Even third world countries like Iran have now roads with a second floor e.g. Iran built a second floor of traffic lanes on the highway goes across Tehran [32]. This second floor road is shown in Figure 1. In view of that, any road can be multiplied and the enlargement of the roads can be financed by the money saved from eliminating subsidization of rail systems.

\section{Air Pollution of Rail and Cars are More or Less Equal}

Modern vehicles are produced with advanced Catalytic Converters [33] and in most of the developed countries the installation of Catalytic Converter is enforced [34]. On the whole, modern vehicles, if kept in good condition, emit only a small amount of air quality pollutants [35]. In addition, in most of the developed 
countries, the selling of leaded fuel is forbidden. Lead is a potent neurotoxin and pollutant [36], so most of the developed countries enforce the usage of unleaded fuel and currently unleaded fuels are a widespread standard [37].

In contrast to the developed countries, many developing countries do not regulate the quality of the fuel traded in the gas stations; nor do they regulate the pollution level emitted by vehicles in their roads. In addition, because catalytic converters contain high-priced materials like platinum, palladium, rhodium and gold, stealing of catalytic converters are frequent and there were many cases that the vehicle owner has taken out the catalytic converter of his vehicle and has sold it [38]. In such cases, just the car owner has been paid for the catalytic converter, but his entire neighborhood has breathed the pollutants.

Usually, air pollution level is measured by the values of PM10 and PM2.5; whereas PM10 is particulate matter in diameter of 10 micrometers or less and PM2.5 is particulate matter in diameter of 2.5 micrometers or less [39], so PM2.5 can under no circumstances be greater than PM10.

The maximum legal level of air pollution is almost the same for the most part of the developed world. The World Health Organization requires a maximum level of 50 for PM10 [40] The United States standard is with accordance of this requirement [41]. The standard in most of Europe is more stringent requiring a maximum legal level of 40 for PM10 [42]. The maximum legal level of PM2.5 is 25. This maximum legal level is the same in The United States and Europe and it is with accordance of The World Health Organization maximum level requirement.

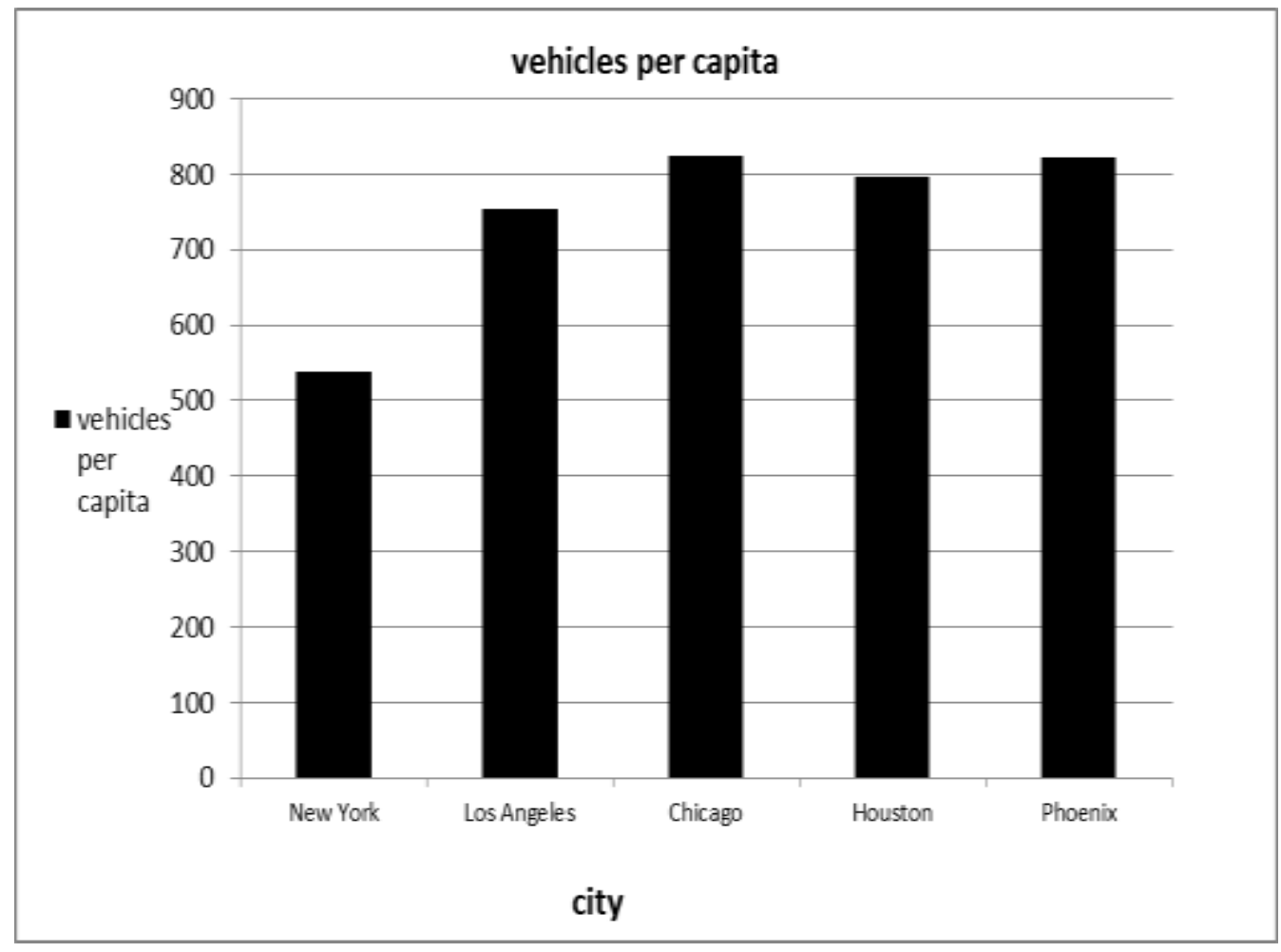

Figure 2. Vehicles Per Capita in the 5 Most Crowded Cities in the US

The United States have a very high number of vehicles per capita -797 which is a much higher number than the common number of vehicle per capita in other countries; however, the average level of air pollution in the 5 most crowded cities in The United States (published by the World Health Organization [43]) are well below the maximum level of both PM10 and PM2.5. The numbers of vehicles per capita in 
the 5 most crowded cities in The United States that were published by the Federal Highway Administration [44] are detailed in Figure 2; whereas the amount of pollutants in the 5 most crowded cities in The United States are detailed in Figure 3. So, despite the large number of vehicles per capita, The United States keep on high quality of air, even in the crowded cities.

In contrast, in many developing countries, the authorities disregard the regulations about air pollution if they exist at all. As a result, the air quality is unacceptably poor.

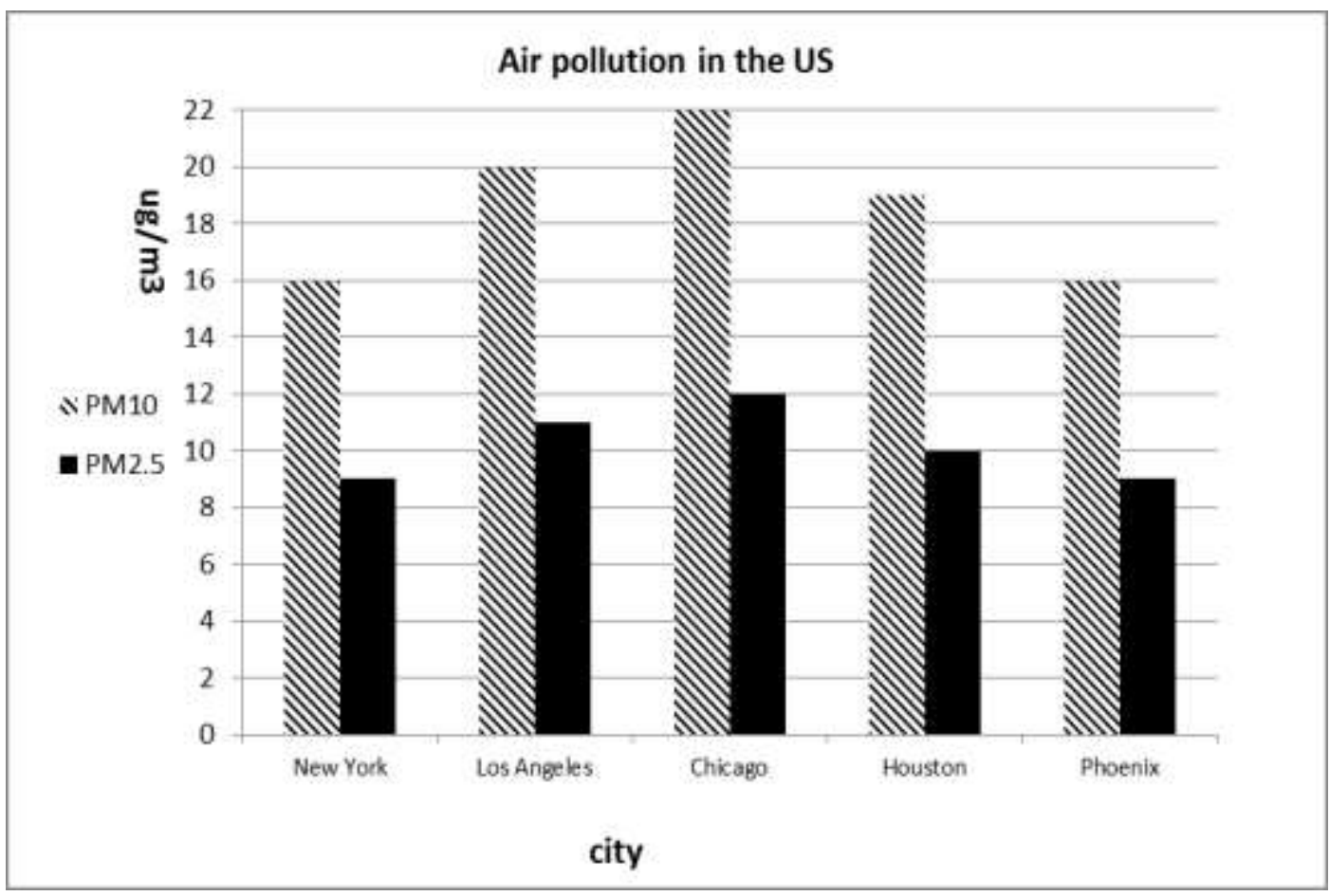

Figure 3. Air Pollution in the 5 Most Crowded Cities in the US

If we look for example at Pakistan, we will find that Pakistan has much higher concentrations of both PM10 and PM2.5. The data about the concentrations of PM10 and PM2.5 is shown in Figure 4 and we can see that the concentrations are much higher than the maximum level required by The World Health Organization; however, it is amazing that Pakistan has only 13 vehicles per capita! [45] which is only $1.63 \%$ of vehicles per capita in The United States.

So the case of The United States shows that even large number of modern private vehicles almost does not pollute the air of the crowded cities. The reason for polluted air is for the most part generated by substandard vehicles, leaded fuel and fuels mixed with oils that are outlawed in developed countries. And so, the emission of the vehicles travel in Pakistan is not the explanation for the enormous immoderation in the concentration of pollutants in the air of Pakistan, but rather the quality and the condition of these vehicles. 


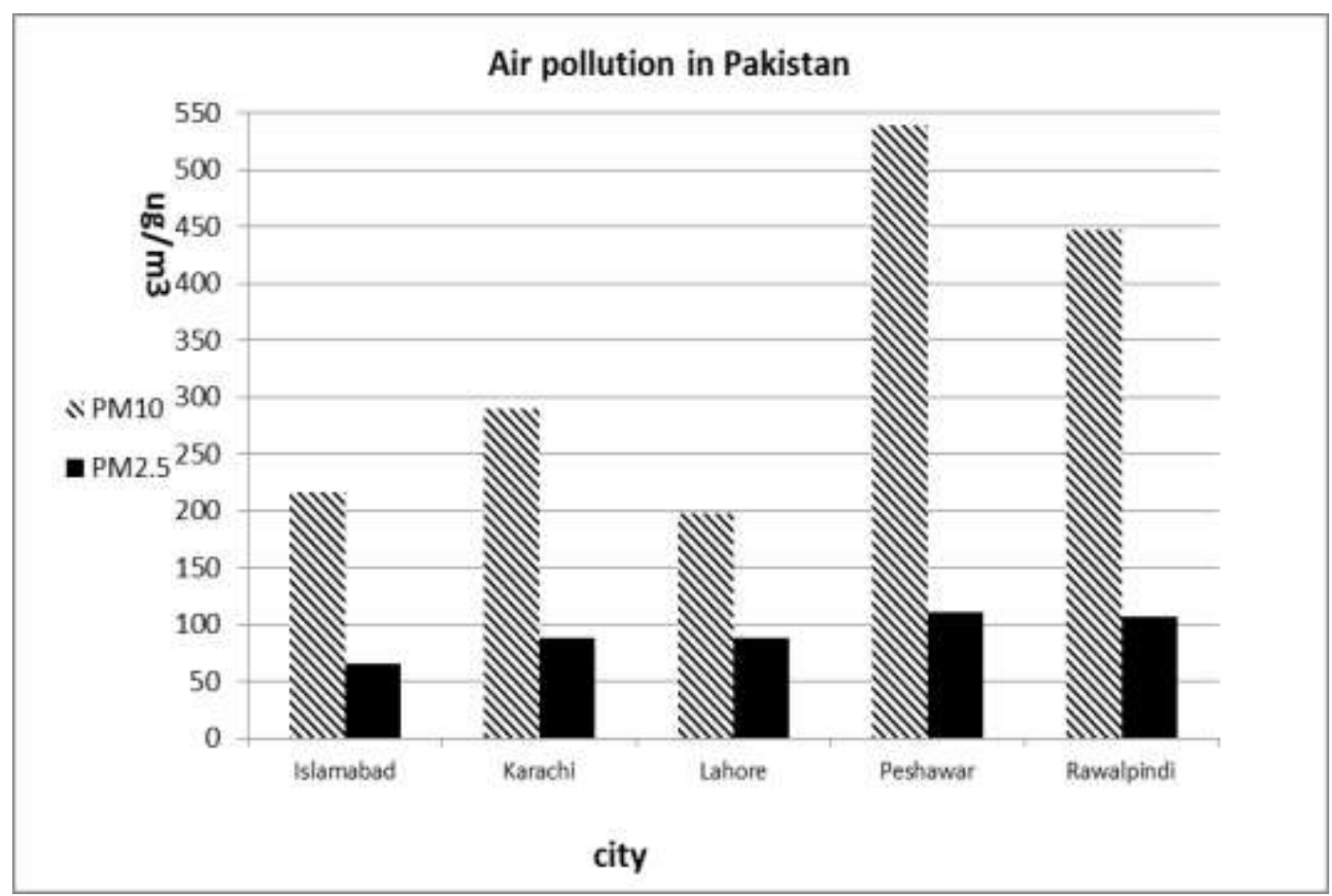

Figure 4. Air Pollution in the 5 Most Crowded Cities in Pakistan

Besides, there are more whys and wherefores the poor air quality in Pakistan like inappropriate waste treatment as burning of waste as is shown in Figure 5. Also, emission of pollutants from industrial plants near living area contributes to the poor air quality in Pakistan.

The pollutants emitted from private vehicles have been considerably reduced during last years and so this notorious emission is no longer an acute concern. For that reason, it is irrational to devote billions of dollars so as to subsidize rail systems which will contribute almost no impact on air quality.

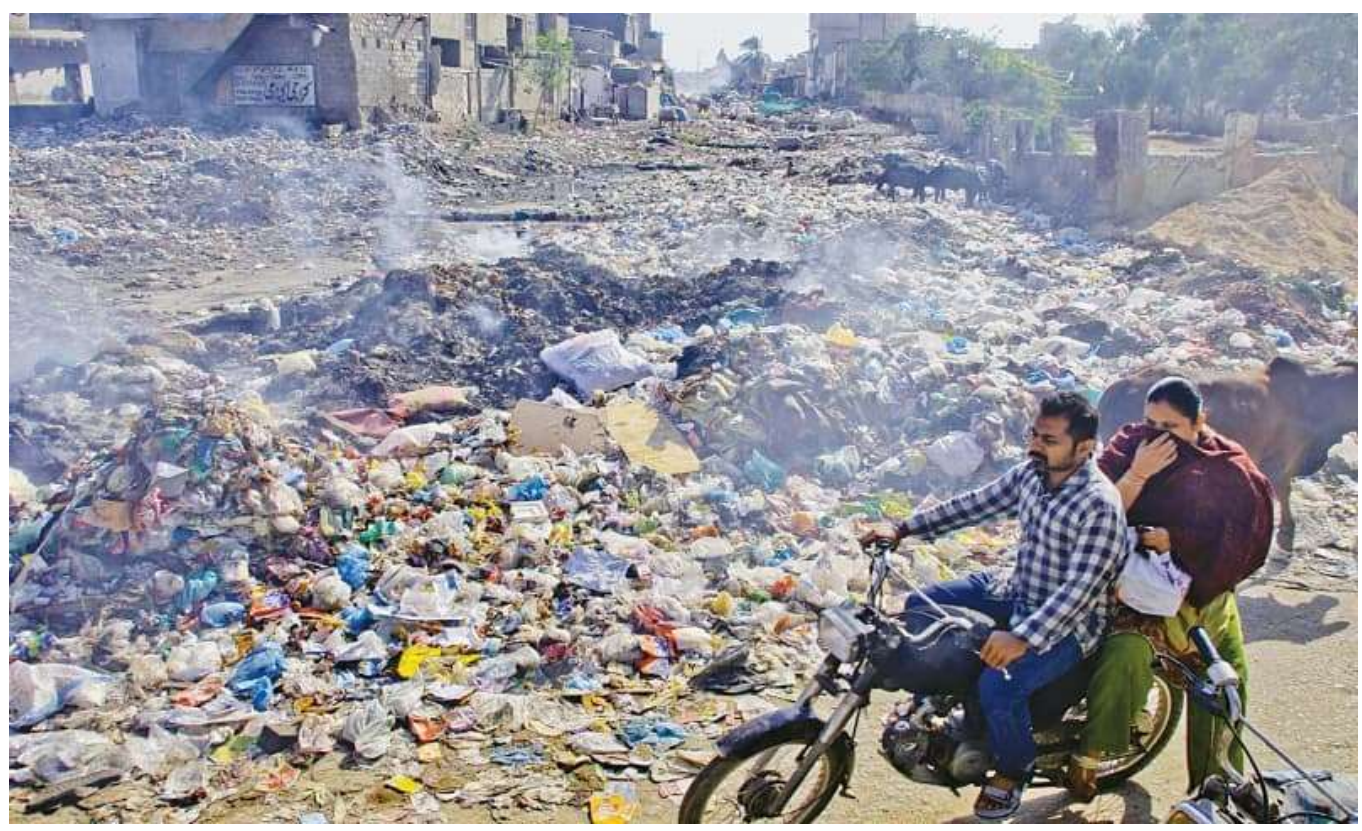

Figure 5. Improper Waste Treatment In Pakistan 


\section{Disableds Will Not Need Rails Anymore}

Even people with disabilities or people working in an exhausting job will be capable to travel in a car without driving in the era of autonomous vehicles [46]; furthermore, trains arrive at a location usually not nearby the passenger destination, whereas shared autonomous vehicle can take the passenger very close to his destination and park itself in a remote location [47,48], so most of the passengers will prefer to travel by autonomous vehicles.

In addition, drunk, reckless, or distracted drivers are rarely aware that their unsafe way of driving can be very harmful. Many authorities endeavor to encourage these drivers to use public transportation like trains instead of driving their cars. These endeavors and efforts, for the most part, are a failure and a waste of money and there are still too many dangerous drivers in the roads, but when the autonomous vehicles are a norm, theses drivers will not drive their cars, but rather a robot will drive the cars and these dangers will be over [49].

The usage of autonomous vehicle will be prevalent soon, so then the needlessness of rail services afforded by government authorities will be unquestionable, because the number of the passengers will be extremely reduced.

\section{Conclusions}

Rails are a means of transportation that was first introduced more than 200 years ago [50]. The concept of trains is transporting many passengers from one central station to another central station. In an era of autonomous vehicles such a concept is obsolete and outdated. The motives for rails specified in the paper and are commonly accepted as compelling motives are no longer good enough and as a result, soon there will be no financial justification for rail systems.

Trains are much less comfortable and restful for passengers than autonomous cars. In addition, train stations are usually not nearby the passenger, so they should be used with another means of transportation so as to arrive at a train station; whereas autonomous cars do not have these connections which are irksome; therefore, autonomous car will gradually take control of the transportation market [51]. As growingly number of autonomous vehicles is on the roads, the rail systems will slowly but surely peter out.

\section{References}

[1] S. Bhattacharjee and A. R. Goetz, "Impact of light rail on traffic congestion in Denver", Journal of Transport Geography, vol. 22, (2012) , pp. 262-270.

[2] R. Emardson, P. Jarlemark, L. Pendrill, C. Sundling, M. E. Nilsson and B. Berglund, "Measurement of accessibility to rail transport systems", In Advanced mathematical and computational tools in metrology and testing, vol. IX, (2012), pp. 136-142.

[3] J. Campos and G. De Rus, "Some stylized facts about high-speed rail: A review of HSR experiences around the world", Transport policy, vol. 16, no. 1, (2009), pp. 19-28.

[4] P. Newman and J. Kenworthy, "The End of Automobile Dependence How Cities Are Moving Beyond Car-Based Planning", Island Press, Washington, DC, (2015).

[5] M. della Cava, "In a self-driving car first, ride with Waymo and there's no driver", (2017), Available online at: https://www.usatoday.com/story/tech/2017/11/07/get-ride-google-and-theres-nodriver/838476001/.

[6] Bureau of Transportation Statistics, "Transportation Fatalities by Mode", U.S. Department of Transportation, Washington, DC, USA, Available online at: https://www.rita.dot.gov/bts/sites/rita.dot.gov.bts/files/publications/national_transportation_statistics/ht $\mathrm{ml} / \mathrm{table}$ _02_01.html_mfd, (2017).

[7] Bureau of Transportation Statistics, "U.S. Vehicle-Miles", U.S. Department of Transportation, Washington, DC, USA, Available online at: https://www.rita.dot.gov/bts/sites/rita.dot.gov.bts/files/publications/national_transportation_statistics/ht ml/table_01_35.html, (2017). 
[8] Y. Wiseman and Y. Giat, "Multi-modal passenger security in Israel", Multimodal Security in Passenger and Freight Transportation: Frameworks and Policy Applications, Edward Elgar Publishing Limited, Chapter 16, (2016), pp. 246-260.

[9] I. Grinberg and Y. Wiseman, "Scalable Parallel Simulator for Vehicular Collision Detection", International Journal of Vehicle Systems Modelling and Testing, Inderscience Enterprises Ltd., vol. 8, no. 2, (2013), pp. 119-144.

[10] [10] I. Grinberg and Y. Wiseman, "Scalable Parallel Simulator for Vehicular Collision Detection", Proc. IEEE Conference on Vehicular Electronics and Safety (IEEE ICVES-2010) Qingdao, ShanDong, China, (2010), pp. 116-121.

[11] I. Grinberg and Y. Wiseman, "Scalable Parallel Collision Detection Simulation", Proc. Signal and Image Processing (SIP-2007), Honolulu, Hawaii, (2007), pp. 380-385.

[12] Association for Safe International Road Travel, "Annual Global Road Crash Statistics", Available online at: http://asirt.org/Initiatives/Informing-Road-Users/Road-Safety-Facts/Road-Crash-Statistics, (2017)

[13] T. Litman, "Rail transit in America: a comprehensive evaluation of benefits", Victoria Transport Policy Institute, (2015).

[14] [14] Y. Wiseman and I. Grinberg, "Circumspectly Crash of Autonomous Vehicles", Proc. IEEE International Conference on Electro Information Technology (EIT 2016), Grand Forks, North Dakota, USA, (2016), pp. 382-386.

[15] Y. Wiseman and I. Grinberg, "When an Inescapable Accident of Autonomous Vehicles is Looming", International Journal of Control and Automation, Science \& Engineering Research Support Society, vol. 9, no. 6, (2016), pp. 297-308.

[16] Y. Wiseman and I. Grinberg, "Autonomous Vehicles Should Not Collide Carelessly", Advanced Science and Technology Letters, vol. 133, (2016), pp. 223-228.

[17] [17] D. Freeman, "Self-Driving Cars Could Save Millions Of Lives - But There's A Catch", HuffPost, Available online at: https://www.huffingtonpost.com/entry/the-moral-imperative-thats-driving-therobot-revolution_us_56c22168e4b0c3c550521f64,(2016).

[18] Y. Wiseman, "Take a Picture of Your Tire!", Proc. IEEE Conference on Vehicular Electronics and Safety (IEEE ICVES-2010) Qingdao, ShanDong, China, (2010), pp. 151-156.

[19] Y. Wiseman, "Camera That Takes Pictures of Aircraft and Ground Vehicle Tires Can Save Lives", Journal of Electronic Imaging, vol. 22, no. 4, (2013), p. 041104.

[20] Y. Wiseman, "The Effectiveness of JPEG Images Produced By a Standard Digital Camera to Detect Damaged Tyres", World Review of Intermodal Transportation Research, vol. 4, no. 1, (2013), pp. 23-36.

[21] T. C. Folsom, "Energy and autonomous urban land vehicles", IEEE Technology and Society Magazine, vol. 31, no. 2, (2012), pp. 28-38.

[22] P. Fernandes and U. Nunes, "Platooning with IVC-enabled autonomous vehicles: Strategies to mitigate communication delays, improve safety and traffic flow", IEEE Transactions on Intelligent Transportation Systems, vol. 13, no. 1, (2012), pp. 91-106.

[23] D. Carlino, M. Depinet, P. Khandelwal and P. Stone, "Approximately orchestrated routing and transportation analyzer: Large-scale traffic simulation for autonomous vehicles", In 15th International IEEE Conference on Intelligent Transportation Systems (ITSC), (2012), pp. 334-339.

[24] A. Henry, R. E. Barone, A. Pichardo, E. Roach, T. Keegan, D. Simons, E. Thenhaus and B. Oldenburg, "New Mobility Autonomous Vehicles and the Region", Regional Plan Association (RPA), New-York, Available online at: http://library.rpa.org/pdf/RPA-New-Mobility-Autonomous-Vehicles-and-theRegion.pdf, (2017).

[25] C. Tan, "China to Invest $\$ 128$ Billion in Rail, Push for Global Share", Bloomberg, Available online at: https://www.bloomberg.com/news/articles/2015-03-05/china-to-invest-128-billion-in-rail-expandglobal-market-share, (2015)

[26] European Environment Agency, "Size, structure and distribution of transport subsidies in Europe", Office for Official Publications of the European Communities, Luxembourg, Available online at: https://www.eea.europa.eu/publications/technical_report_2007_3/download, (2007).

[27] Y. Wiseman and Y. Giat, "Red Sea and Mediterranean Sea Land Bridge via Eilat", World Review of Intermodal Transportation Research, vol. 5, no. 4, (2015), pp. 353-368.

[28] Y. Wiseman, "Real-Time Monitoring of Traffic Congestions", IEEE International Conference on Electro Information Technology (EIT 2017), Lincoln, Nebraska, USA, (2017), pp. 501-505.

[29] Y. Wiseman, "Computerized Traffic Congestion Detection System", International Journal of Transportation and Logistics Management, vol. 1, no. 1, (2017), pp. 1-8.

[30] Y. Wiseman, "Tool for Online Observing of Traffic Congestions", International Journal of Control and Automation, vol. 10, no. 6, (2017), pp. 27-34.

[31] Y. Wiseman, "Blaumilch Canal on Ayalon Highway", Daaton, Available online at: http://www.daaton.co.il/Article.aspx?id=3290, (2015).

[32] About Iran, "Second floor of Sadr highway was inaugurated", Available online at: https://www.youtube.com/watch?v=5G1s0sE5-zc, (2013).

[33] M. K. Modhavadiya and V. M. Makwana, "A Review Paper on Emission Characteristics and Performance of Catalytic Converter”, Diesel Engine, vol. 2, no. 12, (2015). 
[34] Tenneco Automotive Inc., "Catalytic Converters", Tenneco, Available online at: http://www.tenneco.com/catalytic_converters/, (2000).

[35] Y. Wiseman, "Automatic Alert System for Worn Out Pipes in Autonomous Vehicles", International Journal of Advanced Science and Technology, vol. 107, (2017), pp.73-84.

[36] P. L. Tsai and T. H. Hatfield, "Global benefits from the phaseout of leaded fuel", Journal of Environmental Health, vol. 74, no. 5, (2011), pp. 8-15.

[37] G. Heal and H. Kunreuther, "An alternative framework for negotiating climate policies", Climatic Change, vol. 144, no. 1, (2017), pp. 29-39.

[38] M. A. Johnson , "Stolen in 60 Seconds: The Treasure in Your Car. As Precious Metals Prices Soar, Catalytic Converters Are Targets for Thieves", BNCNEWS, Available online at: http://www.nbcnews.com/id/23117250\#.Wi5OvlVsaUk, (2008).

[39] C. Monn and S. Becker, "Cytotoxicity and induction of proinflammatory cytokines from human monocytes exposed to fine (PM2. 5) and coarse particles (PM10-2.5) in outdoor and indoor air", Toxicology and applied pharmacology, vol. 155, no. 3, (1999), pp. 245-252.

[40] World Health Organization, "WHO Air quality guidelines for particulate matter, ozone, nitrogen

[41] dioxide and sulfur dioxide", WHO Press, Geneva, Switzerland, Available online at: http://whqlibdoc.who.int/hq/2006/WHO_SDE_PHE_OEH_06.02_eng.pdf, (2006).

[42] Environmental Protection Agency, "National Ambient Air Quality Standards for Particulate Matter; Final Rule", Federal Register, Available online at: https://www.gpo.gov/fdsys/pkg/FR-1997-0718/html/97-18577.htm, vol. 62, no. 138, (1997), pp. 38652-38760.

[43] J. P. Putaud, R. Van Dingenen, A. Alastuey, H. Bauer, W. Birmili, J. Cyrys, H. Flentje, S. Fuzzi, R. Gehrig, H. C. Hansson and R. M. Harrison, "A European aerosol phenomenology - 3: Physical and chemical characteristics of particulate matter from 60 rural, urban, and kerbside sites across Europe", Atmospheric Environment, vol. 44, no. 10, (2010), pp. 1308-1320.

[44] World Health Organization, "Ambient (outdoor) air pollution database, by country and city", Available online at: http://www.who.int/entity/phe/health_topics/outdoorair/databases/who-aap-databasemay2016.xlsx?ua=1, (2016).

[45] Federal Highway Administration, "State Motor-Vehicle Registrations - 2015", Available online at: https://www.fhwa.dot.gov/policyinformation/statistics/2015/mv1.cfm, (2017).

[46] Trading Economics, "Pakistan - Motor vehicles", Available online at: https://tradingeconomics.com/pakistan/motor-vehicles-per-1-000-people-wb-data.html, (2010).

[47] B. Sucu, and E. Folmer, "The blind driver challenge: steering using haptic cues", In Proceedings of the 16th international ACM SIGACCESS conference on Computers \& accessibility, (2014), pp. 3-10.

[48] Y. Wiseman, "Remote Parking for Autonomous Vehicles", International Journal of Hybrid Information Technology, vol. 10, no. 1, (2017), pp. 313-324.

[49] Y. Wiseman, "Self-Driving Car - A Computer will Park for You", International Journal of Engineering \& Technology for Automobile Security, vol. 1, no. 1, (2017), pp. 9-16.

[50] N. Kalra and S. M. Paddock. "Driving to safety: How many miles of driving would it take to demonstrate autonomous vehicle reliability?", Transportation Research Part A: Policy and Practice, vol. 94, (2016), pp. 182-193.

[51] H. W. Dickinson. "A Short History of the Steam Engine", Cambridge University Press, New-York, USA, (2011).

[52] R. Sparrow and M. Howard, "When human beings are like drunk robots: Driverless vehicles, ethics, and the future of transport", Transportation Research Part C: Emerging Technologies, vol. 80, (2017), pp. 206-215.

\section{Author}

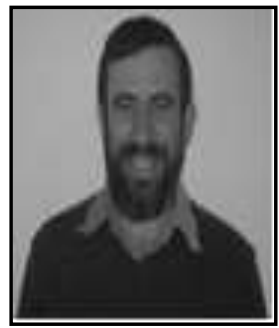

Yair Wiseman, he received the M.Sc. (summa cum laude) and Ph.D. degrees from Bar-Ilan University, the first Post-Doctoral degree with the Hebrew University of Jerusalem, and the second Post-Doctoral degree with the Georgia Institute of Technology.

His research interests include autonomous vehicles, intelligent transportation systems, embedded systems, real-time systems, computational transportation science, operating systems, and process scheduling.

Dr. Wiseman has authored two books. He is on the editorial board of several journals, a member of dozens of conference committees and a reviewer of many scholarly journals.

Dr. Wiseman has been teaching in many institutes including BarIlan University, The Hebrew University of Jerusalem and Israel 
Aircraft Industry and has been supervising many graduate students. An interesting point is that Albert Einstein is Dr. Wiseman's academic great-great-grandfather (i.e. the advisor of the advisor of the advisor of Dr. Wiseman's advisor).

Dr. Wiseman has collaborated with other partners and received research grants to run an active laboratory from inter alia Sun Microsystems, Intel, and Polak Foundation.

Dr. Wiseman is an international expert who has reviewed and evaluated several large projects of the European Union, Israel Science Foundation, Marie Skłodowska-Curie actions in Ireland, Ministry of Education and Science of Kazakhstan. His papers have been published in many venues around the world. 